\title{
The Impact of Abuse on the Quality of Life of the Elderly: A Population-based Survey in Iran
}

\author{
Behnam Honarvar' ${ }^{1}$, Zahra Gheibi ${ }^{1,2}$, Abdolrahim Asadollahi ${ }^{3}$, Farzaneh Bahadori ${ }^{3}$, Elahe Khaksar', \\ Maryam Rabiey Faradonbeh ${ }^{3}$, Mohammad Farjami ${ }^{4}$ \\ ${ }^{1}$ Health Policy Research Center, Institute of Health, Shiraz University of Medical Sciences, Shiraz, Iran; ${ }^{2}$ Department of Epidemiology, Shiraz \\ University of Medical Sciences, Shiraz, Iran; ${ }^{3}$ Department of Healthy Aging, School of Health, Shiraz University of Medical Sciences, Shiraz, Iran; \\ ${ }^{4}$ Department of Biostatistics, Shiraz University of Medical Sciences, Shiraz, Iran
}

Objectives: The quality of life (QoL) of the elderly and elder abuse are growing public health concerns. This study aimed to evaluate the prevalence of abuse and the association between QoL and abuse in older adults.

Methods: Multistage random cluster sampling, along with valid QoL (LEIPAD: LElden, the Netherlands; PADua, Italy; Helsinki, Finland) and abuse questionnaires, were used to assess QoL and elder abuse. Path analysis was performed using Mplus. SPSS and AMOS were used for the other analyses.

Results: A total of 386 elderly individuals with a mean age of $68.00 \pm 6.10$ years were interviewed, of whom 200 (51.8\%), 289 (74.9\%), and 376 (97.4\%) were women, educated, and married, respectively. Moreover, 167 (43.2\%) had low-to-moderate QoL, and 108 (27.9\%) had experienced a moderate level of abuse. QoL and abuse were inversely associated $(r=-0.253)$, with men $(\beta=-0.24)$ more affected than women $(\beta=-0.21)$. Musculoskeletal disorders were also strong determinants of $Q o L$ in the elderly. QoL was strongly associated with emotional abuse, while abuse was highly related to the social component of QoL. Furthermore, emotional abuse was the type of abuse most significantly associated with the self-care, depression/anxiety, cognitive, and social components of QoL. Sexual abuse, violation of personal rights, and neglect were the main determinants of the physical functioning, life satisfaction, and sexual domains of QoL, respectively.

Conclusions: Nearly half of the elderly individuals lacked a high QoL, and at least one-fourth had experienced some form of abuse. Elder abuse was correlated inversely with QoL. Therefore, preventive interventions are recommended to decrease elder abuse in the family, community, and other settings.

Key words: Elder, Quality of life, Abuse, Violence, Gender, Path analysis

Received: July 22, 2019 Accepted: December 10, 2019

Corresponding author: Zahra Gheibi, MSc

Department of Epidemiology, Shiraz University of Medical Sciences,

Shiraz 7153675541, Iran

E-mail: gheibizahra@gmail.com

This is an Open Access article distributed under the terms of the Creative Commons Attribution Non-Commercial License (https://creativecommons.org/licenses/bync/4.0/) which permits unrestricted non-commercial use, distribution, and reproduction in any medium, provided the original work is properly cited.

\section{INTRODUCTION}

The aging of the world population affects developing countries more intensely than developed nations [1]. According to the World Health Organization (WHO), the elderly population worldwide is projected to increase from $11 \%$ in 2006 to $22 \%$ in 2050 [2]. According to the Statistical Center of Iran [3], elderly individuals accounted for $9.3 \%$ of the total Iranian population, and this is projected to increase to $10 \%$ by 2026 [4]. 
Older individuals are vulnerable to physical and mental disabilities, loneliness, isolation, and a lack of social support [5]. Therefore, attention to this stage of life, especially with regard to the emotional, economic, psychological, and social dimensions, is necessary [1]. In addition, abuse is among the potential threats to the elderly, and public concern regarding this threat is growing $[1,4]$. However, elder abuse is still a neglected issue in both health policy and research [4-6] and is underreported, meaning that the problem may be even more severe than anticipated $[5,6]$. Elder abuse is defined as a single or repeated act, or the lack of appropriate action, occurring within any relationship in which there is an expectation of trust, where such an act or lack of action causes harm or distress to an older person [2]. Elder abuse can be categorized as physical, psychological, financial, or sexual [1]. It may also include the violation of personal rights and neglect [1]. The WHO reported that around 1 in 6 people aged 60 years and older experience some form of abuse in their communities annually $[7,8]$. Furthermore, the prevalence of elder abuse has been reported to be $1-15 \%$, and it may impact 1 in 10 elderly individuals each month [1]. A systematic review demonstrated that the prevalence of elder abuse is $15.7 \%$ [5]. The prevalence of elder abuse differs across settings such as families, communities, and institutions such as nursing homes and hospitals [7]. Additionally, quality of life (QoL) is an important phenomenon in relation to the elderly, and its improvement is another common topic of public interest [9]. Few studies have evaluated the relationship between elder abuse and the QoL of elderly people [10]. The present study aimed to determine the associations of elder abuse and its components with QoL and its domains among the elderly population.

\section{METHODS}

\section{Sample Size Calculation and Sampling Technique}

The present cross-sectional and population-based study took place between July 2018 and February 2019 in Shiraz, the capital of Fars Province in the south of Iran. Of a total population of 2 million, this city has approximately 180000 individuals of at least 60 years old. This population is covered by 3 public health networks affiliated with the medical university of Shiraz. Each of these health networks includes several health centers, and each health center covers a population of around 50000 individuals on average. Nearly $95 \%$ of elderly people are covered by these centers. The sample size was calculated as 421 , con- sidering a mean prevalence of elder abuse of $24 \%$ [11], $95 \%$ precision, a 95\% confidence level, and a design effect of 1.5 based on multiple steps of sampling. Multistage random cluster sampling was utilized to select the participants. First, the proportion of the elderly population in each of the 3 health networks was defined. Next, several clusters (centers) were randomly selected from the list of the health centers in each network. Then, the proportion of the sample size in each cluster was defined based on the list of registered elderly individuals, followed by selecting the necessary sample of elderly subjects by using systematic randomization in each selected health center. In addition, the phone numbers of the selected individuals were extracted from their records, and trained interviewers introduced themselves and described the study objectives to the elderly individuals or their families through phone calls. For those who were willing and able to participate, appointments were made and interviews were conducted. According to the study protocol, elderly individuals were excluded and replaced by another individual if their families reported that the elderly person had dementia or Alzheimer disease on the phone call. The elderly participants were then invited to the university-affiliated Motahari Clinic on Zand Street in Shiraz. Additionally, they were given the phone numbers of 2 researchers involved in the study so that the participants could ask any possible questions.

\section{Data-gathering Methods and Instruments}

In the clinic, detailed explanations were provided to each of the subjects, and data regarding demographic, socioeconomic, and medical characteristics were collected in face-to-face interviews. The collected data included information about the subjects' age, gender, education, marital status, financial problems, and chronic pain, as well as cardiovascular, musculoskeletal, chronic liver or kidney diseases, sleep disorders, and history of hospitalization. Furthermore, the LEIPAD (LElden, the Netherlands; PADua, Italy; Helsinki, Finland) questionnaire was used to assess the QoL of the participants. The LEIPAD assessment encompassed 49 items, including 31 core components and 18 moderators. The 31 core questions can be grouped into several subdomains, including cognitive functioning (items 8 , $13,14,15$, and 16), physical functioning (items $1,6,7,9$, and 12 ), self-care (items $2,3,4$, and 5), depression and anxiety (items $17,18,19$, and 20), social functioning (items 21,22 , and 23), sexual connectedness (items 10,11, 24, and 25), and life satisfaction (items 26, 27, 28, 29, 30, and 31). Each item was rated 
on a 4-point categorical scale (from 0 to 3 ) to yield a total maximum score of 93 for the core section. On this scale, scores below 32, between 32 and 62, and above 62 indicated low, moderate, and high QoL, respectively. The Persian version of the LEIPAD questionnaire was utilized to evaluate the participants' QoL [12]. The validity and reliability (Cronbach $\alpha=94 \%$ ) of this questionnaire were approved by expert opinion and based on a previous study of the elderly population, respectively [13]. Additionally, exploratory and confirmatory factor analyses of the LEIPAD questionnaire determined a Kaiser-Meyer-Olkin measure of sampling adequacy equal to 0.83 , and the Bartlett test of sphericity yielded a value of 48 (degree of freedom = $465 ; p \leq 0.05$ ). The analysis of the LEIPAD core subdomains revealed a varimax rotation of 8 factors and a Kaiser normalization with an eigenvalue higher than 65.32 in maximum likelihood and principal component analyses. Supplemental Material 1 demonstrates the goodness-of-fit of the model, confirming its suitability. In addition, its factor structure was demonstrated to be stable. Therefore, the results of this instrument can be trusted for assessing QoL in older adults.

In addition, a researcher-developed questionnaire including 34 questions distributed into 6 domains was used to detect elder abuse. These domains were neglect (9 questions), emotional abuse ( 9 questions), financial exploitation (4 questions), physical abuse (4 questions), the violation of personal rights (4 questions), and sexual abuse (4 questions). A 5-level Likert-type scale (with options of "not at all," "a little," "quite a bit," "rather a lot" and "a lot") was utilized for scoring each item (from 0 to 4), yielding a total maximum score of 136 . Scores below 45 , between 45 and 90, and above 90 indicated low, moderate, and high levels of abuse, respectively. The validity of the questionnaire was confirmed by a panel of psychiatrists and psychologists, and its total reliability was calculated by measuring the Cronbach alpha coefficient (0.78). Furthermore, Cronbach alpha coefficients were computed for the domains of neglect (0.85), emotional abuse (0.79), financial exploitation (0.78), physical abuse (0.83), violation of personal rights $(0.76)$, and sexual abuse (0.71).

\section{Data Analysis}

SPSS version 24.0 (IBM Corp., Armonk, NY, USA), AMOS version 24 (IBM Corp.), and Mplus version 6.12 (IBM Corp.) were utilized for statistical analysis. First, variables with a significant ( $p$-value $<0.2$ ) correlation with elder abuse and QoL were selected; this was followed by running path analysis for both men and women in order to identify the determinants of abuse and QoL and their correlations. Additionally, the correlations between abuse and QoL components were determined, and values of $0.00-0.29,0.30-0.60$, and $>0.60$ were considered to indicate low, moderate, and high levels of correlation, respectively. Furthermore, $p$-values of less than 0.05 were considered to indicate statistical significance in all steps of the final analysis. In addition, the goodness-of-fit of the model was determined by calculating several indices, including the root mean square error of approximation (RMSEA), the Tucker-Lewis index (TLI), and the comparative fit index (CFI). CFI and TLI values above 0.90 and an RMSEA value below 0.08 indicated a good fit of the model.

\section{Ethics Statement}

The protocol of the present study was in line with the ethical principles for medical research involving human subjects outlined in the Declaration of Helsinki, and it was approved and supervised by the Ethics Committee of Shiraz University of Medical Sciences (No. IR.SUMS.REC.1395.S531). Furthermore, consent forms were obtained from the elderly subjects, and they voluntarily participated in the study. Furthermore, they were assured of the confidentiality of their information, and the questionnaires they completed were anonymous. Additionally, the participants were interviewed in a private place and were not charged for the referrals. Finally, the participants were allowed to withdraw from the study at any time if desired, and they were referred to related specialists if they required a clinical evaluation.

\section{RESULTS}

A total of 421 elderly individuals were invited to participate in the study, of whom 386 individuals accepted and attended the medical clinic, constituting a response rate of $91.6 \%$. No cases of dementia or Alzheimer disease were observed. The mean age of the interviewees was $68.00 \pm 6.10$ years, and 200 (51.8\%) of them were women. In addition, 289 (74.9\%) and $376(97.4 \%)$ of the participants were educated and married, respectively (Table 1 ). The mean score for the core components of QoL was 63.07 \pm 8.71 (out of 93), with a median of 64 and an interquartile range (IQR) of 58-70. Two (0.5\%) participants had low QoL, while 165 (42.7\%) and 212 (54.9\%) had moderate and high QoL, respectively. One hundred and seven (53.5\%) of women and 60 (32.3\%) of men had low and moder- 
Table 1. Demographic, social, financial, and medical characteristics of elderly women and men

\begin{tabular}{|c|c|c|c|}
\hline Variabls & Women $(n=200)$ & Men (n=186) & $p$-value \\
\hline Age, mean \pm SD (y) & $67.21 \pm 5.82$ & $68.91 \pm 6.43$ & 0.008 \\
\hline Education & & & $<0.001$ \\
\hline Illiterate & $56(28.0)$ & $41(22.0)$ & \\
\hline Educated & $144(72.0)$ & $145(78.0)$ & \\
\hline Marital status & & & 0.240 \\
\hline Single & $7(3.5)$ & $3(1.6)$ & \\
\hline Married & $193(96.5)$ & $183(98.4)$ & \\
\hline Financial decision-maker & & & $<0.001$ \\
\hline Elderly person & $73(36.5)$ & $171(91.9)$ & \\
\hline Other & $127(29.9)$ & $15(8.1)$ & \\
\hline Cardiovascular disease & & & 0.090 \\
\hline No & $117(58.5)$ & $241(62.4)$ & \\
\hline Yes & $83(45.5)$ & $145(37.6)$ & \\
\hline Musculoskeletal disease & & & 0.810 \\
\hline No & $166(83.0)$ & $156(83.9)$ & \\
\hline Yes & $34(17.0)$ & $30(16.1)$ & \\
\hline Chronic pain & & & $<0.001$ \\
\hline No & $25(12.5)$ & $86(46.2)$ & \\
\hline Yes & $175(87.5)$ & $100(53.8)$ & \\
\hline Chronic disease & & & 0.003 \\
\hline No & $171(58.5)$ & $176(94.6)$ & \\
\hline Yes & $29(14.5)$ & $10(5.4)$ & \\
\hline Hospitalization & & & 0.680 \\
\hline No & $47(23.5)$ & $47(25.3)$ & \\
\hline Yes & $153(76.5)$ & $139(74.7)$ & \\
\hline Sleep disorder & & & $<0.001$ \\
\hline No & 70 (35.0) & $103(55.4)$ & \\
\hline Yes & $130(65.0)$ & $83(44.6)$ & \\
\hline
\end{tabular}

Values are presented as number (\%).

SD, standard deviation.

ate QoL. For 7 (1.8\%), we could not classify their level of QoL, due to their incompleteness of their questionnaires. With regard to abuse, the mean score for all interviewees was 38.96 \pm 10.16 (out of 136), with a median of 36 and an IQR of 32-46. Based on the results, low QoL was more frequent among illiterate (uneducated) women (35.7\%) and men (19.5\%). Overall, 227 (58.8\%) participants had experienced a low level of abuse, while 108 (27.9\%) had experienced a moderate level of abuse. No participant was found to have experienced a high level of abuse. A total of $62(31.0 \%)$ of women and $46(24.7 \%)$ of men had experienced moderate level of abuse in their lives. Similarly to the findings regarding low QoL, illiterate women (53.6\%) and men (58.5\%) tended to have experienced more abuse than educated participants. Furthermore, 78 (39.0\%) of women and 5 (2.7\%) of men had been financially abused.

Overall, Pearson correlation of QoL and abuse were inversely correlated $(r=-0.253)$. The results of the path analysis indicate that abuse had a direct and inverse effect on QoL, although the effect differed between men and women (Figure 1). As shown in Figure $1 A$, chronic disease $(\beta=-0.23)$ and elder abuse $(\beta=-0.21)$ had the strongest direct, but inverse, effects on the QoL of women. Furthermore, in women, musculoskeletal and cardiovascular diseases were positively associated with the experience of abuse, while they were indirectly associated with decreased QoL. Additionally, cardiovascular disease $(\beta=-0.19)$, financial exploitation ( $\beta=-0.18)$, education level $(\beta=0.14)$, and sleep disorders $(\beta=-0.14)$ had direct effects on QoL. In men, elder abuse $(\beta=-0.24)$ and musculoskeletal diseases $(\beta=-0.20)$ were the most effective correlates of QoL and were found to decrease QoL directly (Figure 1B). In addition, hospitalization was found to indirectly and inversely influence QoL through abusive behavior (Figure 1B). Furthermore, in men, chronic $(\beta=-0.18)$ and cardiovascular diseases $(\beta=-0.16)$ were also negatively associated with QoL. In contrast, education level in men was found to have both direct and indirect positive associations with QoL (Figure 1B). Table 2 shows the correlations between the core components of QoL, as well as the correlations between the domains of abuse and the inter-correlations between QoL components and abuse domains. Of the correlations between the components of elder abuse, the most significant correlations were observed between physical abuse and the violation of personal rights $(r=0.731)$, emotional abuse and physical abuse $(r=0.716)$, emotional abuse and the violation of personal rights $(r=0.614)$, financial exploitation and physical abuse $(r=0.596)$, and emotional abuse and financial exploitation $(r=0.539)$. Regarding the associations between the components of QoL and abuse, the total QoL score had the strongest association with the emotional component of abuse ( $\beta=-0.34 ; p<0.001)$, and the total abuse score had the strongest correlation with the social functioning component of $\mathrm{QoL}(\beta=-0.25 ; p<0.001)$. Among the components of QoL, physical functioning was significantly and inversely affected by sexual abuse $(\beta=-0.29 ; p<0.001)$ and emotional abuse $(\beta=$ $-0.28 ; p<0.001)$. However, it was positively $(\beta=0.25 ; p<0.001)$ affected by financial exploitation (Figure $2 A$ ). Self-care was negatively correlated with emotional abuse $(\beta=-0.10 ; p=0.04)$ and positively associated with sexual abuse $(\beta=0.09 ; p=0.05)$, the details of which are illustrated in Figure $2 \mathrm{~B}$. In addition, the results (Figure $2 \mathrm{C}$ ) reveal that the depression and anxiety com- 

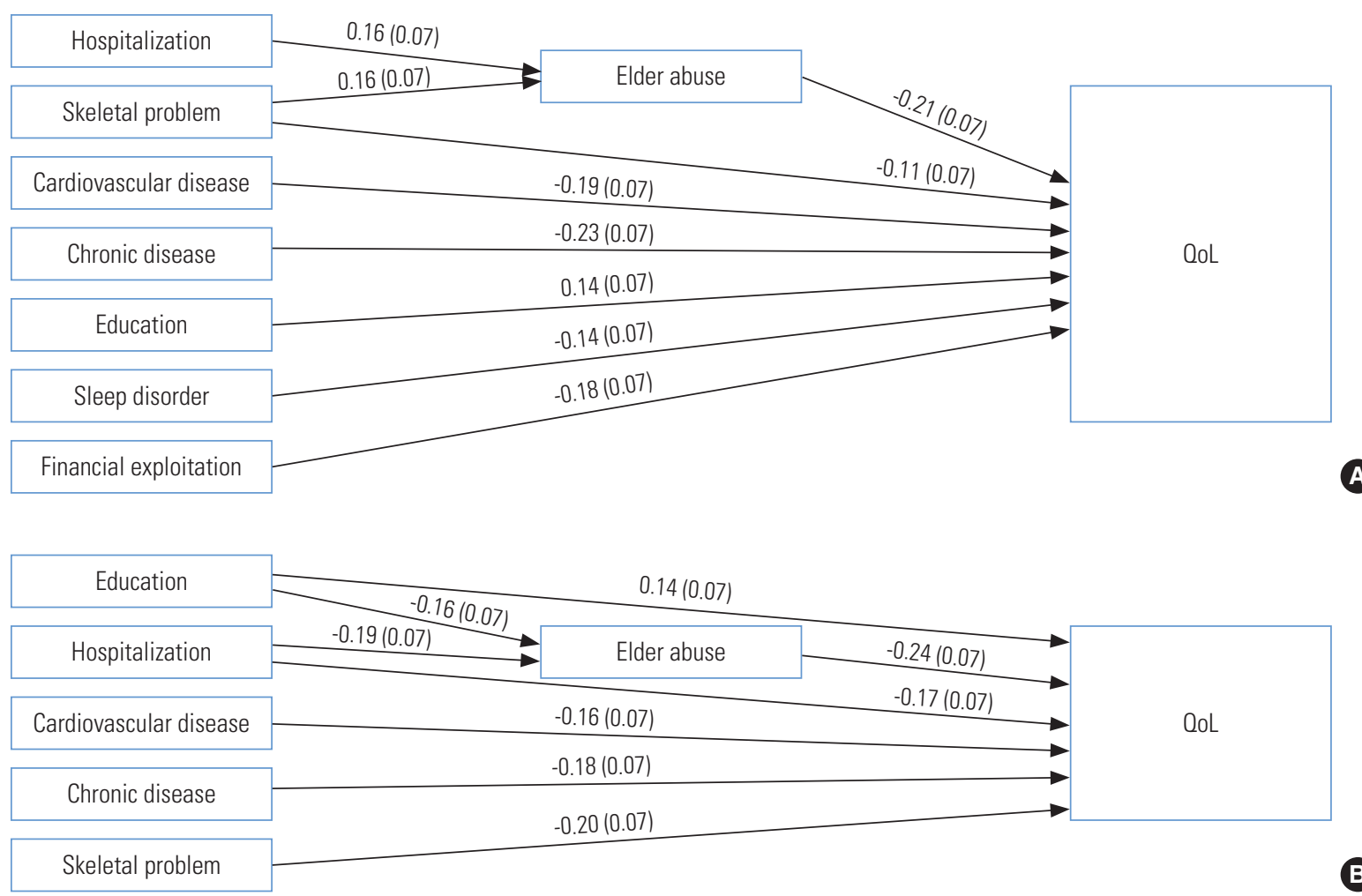

Figure 1. Path diagram of quality of life (QoL) in the elder (A) women, (B) men. Values are presented as standardized coefficient (standard error). All coefficients are significant in 0.05 .

Table 2. Correlations between components of quality of life (QoL) and elder abuse

\begin{tabular}{|c|c|c|c|c|c|c|c|c|c|c|c|c|c|c|}
\hline Variables & Component & 1 & 2 & 3 & 4 & 5 & 6 & 7 & 8 & 9 & 10 & 11 & 12 & 13 \\
\hline \multirow[t]{7}{*}{ OoL } & 1. Physical functioning & 1.000 & & & & & & & & & & & & \\
\hline & 2. Self-care & 0.006 & 1.000 & & & & & & & & & & & \\
\hline & 3. Depression and anxiety & 0.092 & $0.234^{*}$ & 1.000 & & & & & & & & & & \\
\hline & 4. Cognitive functioning & 0.024 & $0.289^{*}$ & $0.463^{*}$ & 1.000 & & & & & & & & & \\
\hline & 5. Social functioning & $0.136^{+}$ & 0.083 & $0.279^{*}$ & $0.211^{*}$ & 1.000 & & & & & & & & \\
\hline & 6. Sexual connectedness & $0.294^{*}$ & $-0.198^{*}$ & $0.159^{*}$ & $-0.160^{*}$ & 0.086 & 1.000 & & & & & & & \\
\hline & 7. Satisfaction & $-0.212^{*}$ & $0.286^{*}$ & $0.314^{*}$ & $0.262^{*}$ & $0.170^{*}$ & $-0.259^{*}$ & 1.000 & & & & & & \\
\hline \multirow[t]{6}{*}{ Abuse } & 8. Neglect & 0.061 & -0.074 & 0.004 & 0.008 & $-0.157^{*}$ & $-0.094^{+}$ & -0.024 & 1.000 & & & & & \\
\hline & 9. Emotional & $-0.172^{*}$ & -0.110 & $-0.289^{*}$ & $-0.187^{*}$ & $-0.216^{+}$ & -0.055 & $-0.233^{*}$ & -0.012 & 1.000 & & & & \\
\hline & 10. Financial & $0.101^{*}$ & $-0.048^{+}$ & $-0.034^{+}$ & -0.134 & -0.117 & -0.009 & -0.126 & 0.054 & $0.539^{*}$ & 1.000 & & & \\
\hline & 11. Physical & -0.077 & -0.075 & -0.120 & $-0.054^{+}$ & -0.187 & -0.029 & -0.139 & 0.031 & $0.716^{*}$ & $0.596^{*}$ & 1.000 & & \\
\hline & 12. Violation of personal rights & -0.062 & -0.052 & -0.146 & -0.132 & -0.174 & -0.035 & -0.178 & 0.011 & $0.614^{*}$ & $0.477^{*}$ & $0.731^{*}$ & 1.000 & \\
\hline & 13. Sexual & $-0.343^{*}$ & 0.087 & -0.067 & -0.046 & -0.037 & -0.044 & 0.012 & -0.091 & 0.130 & 0.029 & 0.113 & $0.181^{*}$ & 1.000 \\
\hline
\end{tabular}

${ }^{+} p<0.1,{ }^{*} p<0.05$.

ponent of QoL was negatively associated with emotional abuse $(\beta=-0.33 ; p<0.001)$, while it was positively correlated with financial exploitation $(\beta=0.18 ; p=0.04)$. As displayed in Figure $2 \mathrm{D}$, cognitive functioning was negatively correlated with emotional abuse $(\beta=-0.21 ; p<0.001)$ and the violation of personal rights $(\beta=-0.13 ; p<0.04)$, while it was positively correlated with physical abuse $(\beta=0.20 ; p=0.004)$. The sexual $(\beta=-0.10 ; p=$ $0.01)$, social $(\beta=-0.19 ; p<0.001)$, and life satisfaction $(\beta=-0.16$; $p<0.001)$ components of QoL were inversely associated with neglect, emotional abuse, and the violation of personal rights, 

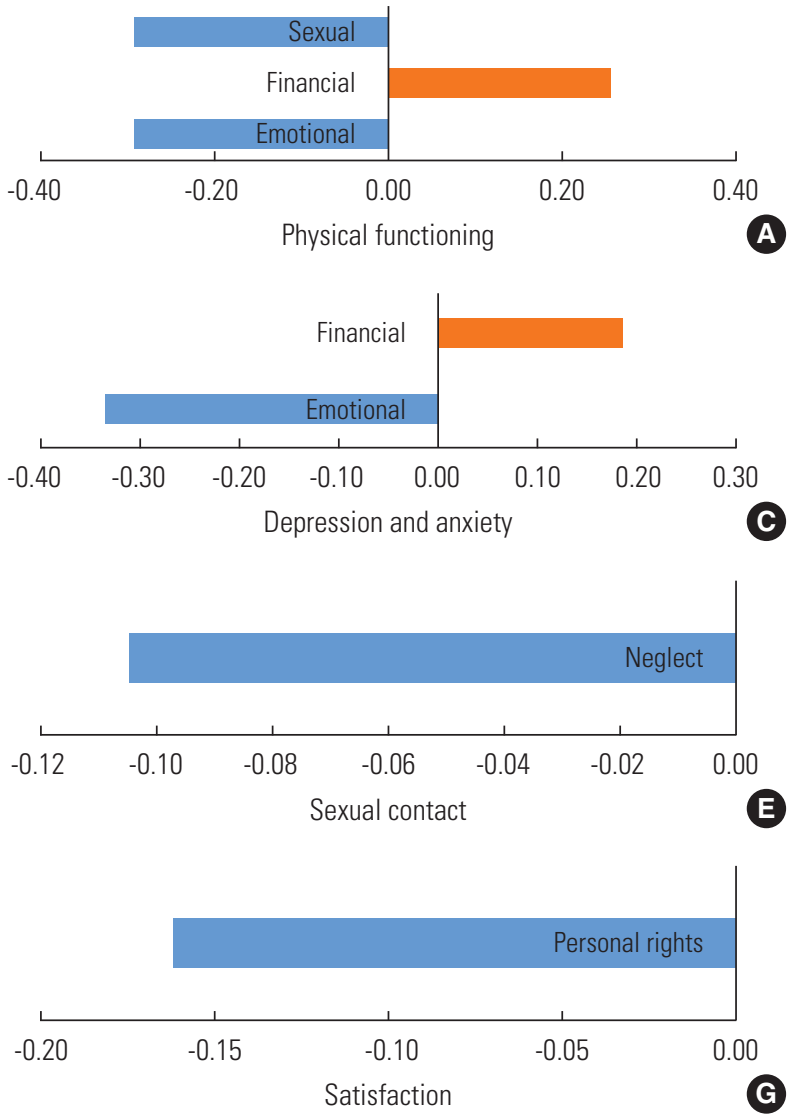

respectively (Figure 2E-2G).

\section{DISCUSSION}

The results of the present study revealed that at least 2 of 5 elderly individuals had low to moderate QoL, and at least 1 of 4 participants had experienced moderate levels of abuse; additionally, QoL and level of abuse were directly and inversely correlated with each other. Furthermore, a significant difference was found between men and women, with women exhibiting lower QoL and experiencing more abuse. Additionally, chronic diseases and abuse were the strongest and inverse determinants of QoL in elder women, while in elder men, abuse and musculoskeletal diseases had the strongest inverse association with QoL. Among the types of abuse, QoL was most strongly correlated with emotional abuse, and among the domains of QoL, abuse was most highly associated with the social functioning component. Thus, the results of the present study establish emotional abuse as the most significant correlate of the QoL components of self-care, depression and anxiety, cognitive functioning, and social functioning, while sexual abuse, the violation of personal rights, and neglect were the
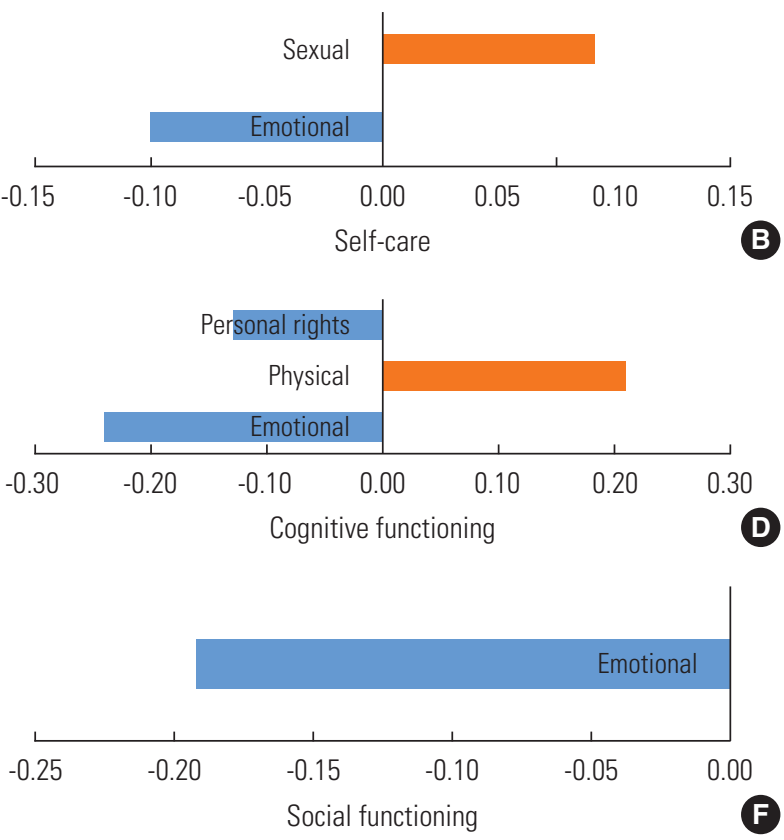

Figure 2. Effect of abuse components on different components of $(A)$ physical functioning, (B) self-care, $(C)$ depression and anxiety, (D) cognitive functioning, (E) sexual contact, (F) social functioning, and (G) satisfactionquality of life in the elders.

most significant determinants of the QoL components of physical functioning, life satisfaction, and sexual connectedness, respectively.

The National Center for Elder Abuse has reported a significant increase in elder abuse since 1986, especially of women [14]. According to a systematic review conducted in 2015, the prevalence of elder abuse in Asian countries ranged from $0.022 \%$ to $62 \%$ [15]. However, the prevalence of this problem in the family setting was approximately $25 \%$, while in the institutional setting it was between $11 \%$ and $24 \%$ [6]. A study in Iran found that the overall prevalence of elder abuse was $56.4 \%$, and its highest and lowest prevalence rates were reported in Tehran (87.8\%) and Shahrekord (17.1\%) Provinces, respectively [16]. Manouchehri et al. [17] revealed that $84.4 \%$ of elderly people visiting the parks of Tehran (in Iran) had experienced a form of emotional abuse. In addition, Yon et al. [7] reported that psychological abuse, financial abuse, neglect, physical abuse, and sexual abuse were the most common types of elder abuse, respectively, while physical, social, emotional, financial, and sexual abuse, along with the violation of personal rights and neglect, were the most common types of elder abuse, respectively, in the present study. In a meta-analysis, Molaei et al. [16] 
found that emotional abuse was the most frequent type of elder abuse, although discrepancies exist in the included studies. They further reported the prevalence of different types of abuse of older adults as follows: neglect (4.5-68.0\%), mental abuse (12.4-59.8\%), financial mismanagement (5.8-40.0\%), physical misconduct (2.8-35.9\%), and isolation (3.7-23.0\%).

Guedes et al. [18] and Ruiz-Pérez et al. [19] concluded that gender and social relationships are 2 important dimensions of experienced violence. Furthermore, Guedes et al. [18] indicated that social characteristics such as family dimensions and low levels of support from partners, children, and family were significantly associated with the presence of psychological disorders. According to Ruiz-Pérez et al. [19], women are at higher risk of violence than men, while among men, those with lower education levels and lower income are at a relatively high risk of violence. Additionally, women, especially those with relatively less education and support, are more likely than men to be subjected to psychological abuse [19].

Some studies have demonstrated that people who have experienced any type of abuse have a lower level of physical and mental health and are more likely to suffer from chronic illnesses and mental disorders, such as depression and memory loss, than people who have not experienced abuse [20]. In addition, they are more likely to have problems with their daily activities [21]. Accordingly, the QoL of older people who have experienced abuse is lower in certain domains than that of those who have not experienced abuse $[10,13,22,23]$. The results of other studies by Fisher and Regan [24] and Schofield and Mishra [25] have also confirmed the role of elder abuse in reducing the physical and mental health and the QoL of the elderly. Based on the results of another study, emotional and financial abuse led to more depression or anxiety [26], while in the present study, emotional abuse reduced the satisfaction component of QoL. In another study from Shiraz, Iran, the emotional form of abuse was found to have the highest prevalence [11], which aligns with the results of the present study. Furthermore, Schiamberg and Gans [27] reported a significant association between neglect and different aspects of QoL. The results of the present study indicated that emotional abuse, physical abuse, and the violation of personal rights were correlated with cognitive functioning. Emotional abuse also caused a reduction in the self-care component of QoL. However, no evidence has been observed in other studies regarding these of associations. Furthermore, the results revealed that sleep disorders had a direct, although inverse, effect on QoL. The findings of another study confirmed that elders with low QoL were relatively more likely to experience sleep disturbances [28].

The present study has some limitations. For data analysis, we used path analysis due to its simplicity and ease of interpretation, compared to structural equation modeling, which is a more complex but stronger model. However, the most and the least important variables are the same in both models. We also determined the associations between variables, but not causal relationships; to assess causality, a longitudinal study would be required. Moreover, the findings of this study are not representative of the entire elderly population of Iran, although they can provide a general picture of the situation for the Iranian elderly residing in large urban areas.

In conclusion, nearly half of the elders in this study did not have a high QoL, and at least one-fourth of them had experienced abuse. Finally, abuse was found to have an inverse association with QoL and its components. These results suggest the importance of preventive interventions to decrease elder abuse in the familial, community, and other settings in order to improve the QoL of the elderly.

\section{SUPPLEMENTAL MATERIALS}

Supplemental material is available at https://doi.org/10. 3961/jpmph.19.210.

\section{CONFLICT OF INTEREST}

The authors have no conflicts of interest to declare for this study.

\section{FUNDING}

None.

\section{ACKNOWLEDGEMENTS}

We thank all the elderly individuals who participated in the present study and answered our questions honestly.

\section{AUTHOR CONTRIBUTIONS}

Conceptualization: BH. Data curation: ZG, EK, FB, MRF, MF. Formal analysis: MF, ZG, AA, EK, FB, MRF. Funding acquisition: None. Methodology: AA, EK, ZG, FB, MF. Project administra- 
tion: $B H$. Visualization: $B H, A A$. Writing - original draft: $B H, E K$, $F B, Z G, M R F$. Writing - review \& editing: BH, ZG, EK, AA, MRF, MF.

\section{ORCID}

Behnam Honarvar https://orcid.org/0000-0002-1081-5778

Zahra Gheibi https://orcid.org/0000-0003-3585-0382

Abdolrahim Asadollahi https://orcid.org/0000-0003-22655641

Farzaneh Bahadori https://orcid.org/0000-0002-1941-9982

Elahe Khaksar https://orcid.org/0000-0002-4531-2337

Maryam Rabiey Faradonbeh https://orcid.org/0000-00033666-0724

Mohammad Farjami https://orcid.org/0000-0003-4170-9297

\section{REFERENCES}

1. Hosseinkhani Z, Moradi Z, Khodamoradi F. Elder abuse: screening in Iranian families. Med J Islam Repub Iran 2017;31:126.

2. World Health Organization. Elder abuse; 2018 [cited 2019 Sep 14]. Available from: https://www.who.int/news-room/factsheets/detail/elder-abuse.

3. Statistical Center of Iran. Census 2016 - general results [cited 2020 Mar 28]. Available from: https://www.amar.org.ir/english/Population-and-Housing-Censuses/Census-2016-General-Results.

4. Tobiasz-Adamczyk B, Brzyski P, Brzyska M. Health-related quality of life in older age and a risk of being a victim of domestic violence. Arch Gerontol Geriatr 2014;58(3):388-398.

5. Wang F, Meng LR, Zhang Q, Li L, Nogueira BO, Ng CH, et al. Elder abuse and its impact on quality of life in nursing homes in China. Arch Gerontol Geriatr 2018;78:155-159.

6. Hirsch RD. Violence against elderly people. Recognize-sensitize-act! Bundesgesundheitsblatt Gesundheitsforschung Gesundheitsschutz 2016;59(1):105-112 (German).

7. Yon Y, Mikton CR, Gassoumis ZD, Wilber KH. Elder abuse prevalence in community settings: a systematic review and metaanalysis. Lancet Glob Health 2017;5(2):e147-e156.

8. Yon Y, Ramiro-Gonzalez M, Mikton CR, Huber M, Sethi D. The prevalence of elder abuse in institutional settings: a systematic review and meta-analysis. Eur J Public Health 2019;29(1): 58-67.

9. Mosqueda L, Burnight K, Gironda MW, Moore AA, Robinson J, Olsen $B$. The abuse intervention model: a pragmatic approach to intervention for elder mistreatment. J Am Geriatr Soc 2016; 64(9):1879-1883.

10. Fraga S, Soares J, Melchiorre MG, Barros H, Eslami B, loannidiKapolou $E$, et al. Lifetime abuse and quality of life among older people. Health Soc Work 2017;42(4):215-222.

11. Kashfi SM, Asadi A, Tabatabaee SH, Yazdankhah M, Jeihooni AK, Rakhshani T, et al. Elder abuse in Shiraz, Iran. Iran J Psychiatry Behav Sci 2017;11(2):e4667

12. De Leo D, Diekstra RF, Lonnqvist J, Lonnqvist J, Cleiren MH, Frisoni GB, et al. LEIPAD, an internationally applicable instrument to assess quality of life in the elderly. Behav Med 1998; 24(1):17-27.

13. Hesamzadeh A, Maddah SB, Mohammadi F, Fallahi Khoshknab M, Rahgozar M. Comparison of elderlys "quality of life" living at homes and in private or public nursing homes. Iran J Ageing 2010;4(4):66-74 (Persian).

14. Keyghobadi F, Moghaddam Hosseini V, Keyghobadi F, Rakhshani MH. Prevalence of elder abuse against women and associated factors. J Mazandaran Univ Med Sci 2014;24(117): 125-132 (Persian).

15. Yan E, Chan KL, Tiwari A. A systematic review of prevalence and risk factors for elder abuse in Asia. Trauma Violence Abuse 2015;16(2):199-219.

16. Molaei M, Etemad K, Taheri Tanjani P. Prevalence of elder abuse in Iran: a systematic review and meta analysis. Iran J Ageing 2017;12(2):242-253 (Persian).

17. Manouchehri H, Ghorbi B, Hosseini M, Nasiri ON, Karbakhsh M. Degree and types of domestic abuse in the elderly referring to parks of Tehran. Adv Nurs Midwifery 2009;18(63):39-45 (Persian).

18. Guedes DT, Alvarado BE, Phillips SP, Curcio CL, Zunzunegui MV, Guerra RO. Socioeconomic status, social relations and domestic violence (DV) against elderly people in Canada, Albania, Colombia and Brazil. Arch Gerontol Geriatr 2015;60(3):492-500.

19. Ruiz-Pérez I, Rodríguez-Barranco M, Cervilla JA, Ricci-Cabello I. Intimate partner violence and mental disorders: co-occurrence and gender differences in a large cross-sectional population based study in Spain. J Affect Disord 2018;229:69-78.

20. Humphries KH, Izadnegahdar M, Sedlak T, Saw J, Johnston N, Schenck-Gustafsson $\mathrm{K}$, et al. Sex differences in cardiovascular disease - impact on care and outcomes. Front Neuroendocrinol 2017;46:46-70.

21. Micheli K, Ratsika N, Vozikaki M, Chlouverakis G, Philalithis A. Family ties and functional limitation in the elderly: results from the Survey of Health Ageing and Retirement in Europe (SHARE). 
Arch Gerontol Geriatr 2018;78:23-29.

22. Heravi-Karimooi M, Rejeh N, Montazeri A. Health-related quality of life among abused and non-abused elderly people: a comparative study. Payesh 2013;12(5):479-488 (Persian).

23. Mohebi L, Heravi-Karimooi M, Zahednezhad S. Comparison of the rates and types of domestic elder abuse and the impact on their quality of life in Dezful. Nova J Med Biol Sci 2015;4(4): 1-9.

24. Fisher BS, Regan SL. The extent and frequency of abuse in the lives of older women and their relationship with health outcomes. Gerontologist 2006;46(2):200-209.

25. Schofield MJ, Mishra GD. Three year health outcomes among older women at risk of elder abuse: women's health Australia. Qual Life Res 2004;13(6):1043-1052.

26. Yan E, Tang CS. Prevalence and psychological impact of Chinese elder abuse. J Interpers Violence 2001;16(11):1158-1174.

27. Schiamberg LB, Gans D. Elder abuse by adult children: an applied ecological framework for understanding contextual risk factors and the intergenerational character of quality of life. Int J Aging Hum Dev 2000;50(4):329-359.

28. Lankarani K, Fard TR. The prevalence and predictors of sleep disturbance in the elderly: a population-based study in Shiraz, Iran. Shiraz E-Med J 2019;20(11);e88349. 